\title{
Inactivation of Dicer 1 in Steroidogenic factor 1-positive cells reveals tissue-specific requirement for Dicer 1 in adrenal, testis, and ovary
}

\author{
Chen-Che J Huang and Humphrey HC Yao*
}

\begin{abstract}
Background: The synthesis of microRNA (miRNA) is a multi-step process that requires the action of the ribonuclease Dicer1. Dicer1 is responsible for the final processing of miRNA and has been implicated in cellular processes such as proliferation, apoptosis, and differentiation. Mouse embryos lacking Dicer1 die in early embryogenesis. In this study, we investigated whether Dicer 1 is required for development of adrenal, testis, and ovary in mouse embryos.

Results: To target Dicer1 deletion specifically in developing adrenals and gonads, we used Steroidogenic factor 1-cre ( $\mathrm{Sf1/Cre)} \mathrm{line} \mathrm{in} \mathrm{which} \mathrm{Cre} \mathrm{recombinase} \mathrm{is} \mathrm{active} \mathrm{in} \mathrm{the} \mathrm{progenitor} \mathrm{cells} \mathrm{of} \mathrm{adrenals} \mathrm{and} \mathrm{gonads.} \mathrm{Lack} \mathrm{of} \mathrm{Dicer} 1$ in the SF1-positive cells did not affect formation and early differentiation of the adrenals and gonads. However, increasing numbers of apoptotic cells were first detected in the Dicer 1 knockout adrenal cortex at 18.5 days post coitum (dpc), followed by apoptosis of somatic cells and germ cells in the testis at postnatal day 0 . Affected adrenal and testes underwent complete degeneration $48 \mathrm{hrs}$ after the onset of apoptosis. However, ovaries were not affected at least until postnatal day 5 , when the animals died due to adrenal insufficiency.

Conclusions: Dicer1 is dispensable for formation and differentiation of fetal tissues derived from the SF1-positive adrenogonadal primordium. Dicer 1 is essential for maintaining cell survival in adrenal and testis; however, development of the ovary from fetal stages to postnatal day 5 does not require the presence of Dicer1. Our results reveal a tissuespecific requirement of Dicerl and microRNAs. Future research is needed to understand how the tissue-specific role of Dicer 1 is established.
\end{abstract}

\section{Background}

Dicer1 gene encodes a protein containing RNase III domains essential for miRNA biogenesis. miRNAs, which are 19-25 nucleotides long, non-coding RNAs, regulate gene expression by binding to target mRNAs in a sequence-specific manner, subsequently inhibiting their translation or inducing their degradation [1-3]. This posttranscriptional gene regulation machinery has been implicated in controlling diverse aspects of development in organisms from plants to mammals. In mice, general knockout (KO) of Dicer1 resulted in embryonic lethality around $7.5 \mathrm{dpc}$ [4]. Inability of Dicer1 KO embryonic stem cells to develop further highlights the role of miRNA machinery in maintaining stem cell population at early developing stages. Results from the tissue-specific

\footnotetext{
* Correspondence: hhyao@illinois.edu

1 Department of Veterinary Biosciences, University of Illinois, Urbana, IL, USA Full list of author information is available at the end of the article
}

KO of Dicer1 gene in mice have demonstrated the importance of miRNAs in organogenesis including heart, lung, limb and gonads [5-11].

Adrenal, testis, and ovary derive from a common primordium when they first arise in embryos. In the mouse embryo around $9.5 \mathrm{dpc}$, cells in the adrenogonadal primordium start to express the orphan nuclear receptor $S f 1$ [also known as Nr5a1, Ad4BP, or Ftzf1 (OMIM 184757)] [12]. Between 10-11 dpc, the adrenogonadal primordium divides into adrenal primordium and gonadal primordium $[13,14]$. The SF1-positive cells eventually differentiate into the cortical cells of the adrenal, Sertoli and Leydig cells of the testis, and granulosa and theca cells of the ovary.

The shared origin of SF1-positive cells in adrenal and gonads raise the possibility that a common regulatory mechanism is present for the establishment or maintenance of these cell lineages. Importance of Dicer1 and 
miRNAs has been documented in the adult testis and ovary [8-11]. In this study, we developed a mouse model in which Dicer1 gene was inactivated specifically in the SF1-positive cells in the adrenogonadal primordium, allowing us to study the overall functions of miRNAs in the development of adrenal, testis and ovary.

\section{Results}

Ablation of Dicer1 in SF1-positive cells causes prenatal degeneration of the adrenal cortex

To investigate the functions of Dicer 1 in development of adrenals and gonads, we generated a conditional $\mathrm{KO}$ model in which Dicer1 alleles were inactivated specifically in the SF1-positive cells, the precursors for cortical cells in the adrenals and somatic cells in the gonads [15]. The Dicer1-floxed allele has been shown to be a null allele upon Cre recombination in lung, limb, inner ear and germ cells $[5,6,9,16]$. The $S f 1 / C r e$ mouse line expresses high levels of Cre recombinase in the adrenogonadal primordium at $10 \mathrm{dpc}$ [15]. We and others have used this Sf1/Cre line to remove or activate genes in the adrenogonadal primordium and observed adrenal and gonadal phenotypes at as early as $12.5 \mathrm{dpc}$ [17-19].

Among the three organs (adrenal, testis, and ovary) that derive from the SF1-positive adrenogonadal primordium, the adrenal was the first to show histological/morphological phenotypes in response to the loss of Dicer1. The Dicer1 conditional knockout (or KO, Sf1/Cre; Dicer1 floxedfloxed) adrenals were indistinguishable from the control adrenal (or CT, Dicer1 floxedfloxed or Dicer 1 floxed/+) up to $16.5 \mathrm{dpc}$. At $18.5 \mathrm{dpc}$, the Dicer $1 \mathrm{KO}$ adrenals were significantly smaller than the control and the decrease in size continued thereafter (Figure 1A). At P5, the size of $\mathrm{KO}$ adrenals was only $20 \% \sim 30 \%$ of the control (Figure $1 \mathrm{~A})$. The decreased adrenal size was not the result of general growth retardation based on the fact that the body weights of control and $\mathrm{KO}$ animals were not different (CT, $4.02 \pm 0.9 \mathrm{~g}, \mathrm{n}=27$; KO, $3.52 \pm 0.9 \mathrm{~g}, \mathrm{n}=6$; $\mathrm{p}=0.2$ ). Immunofluorescence for markers of adrenal cortex (SF1) and medulla (tyrosine hydroxylase or $\mathrm{TH}$ ) showed that the differentiation of cortex and medulla occurred properly in the $\mathrm{KO}$ adrenal compared to the control at 16.5 dpc (Figure 1B). However, as the adrenal development progressed, SF1-positive cells in the cortex were decreased in numbers and were almost completely lost at P5 (Figure 1B). Growth of the medulla was not affected in the $\mathrm{KO}$ adrenal over time, but loss of cortical cells resulted in direct contact between the medulla and the adrenal capsule in P5 KO mice (Figure 1B and Additional File 1).

To further examine the functions of the diminishing $\mathrm{KO}$ adrenal cortex, we analyzed the expression of the steroidogenic enzyme 3 3 -hydroxysteroid dehydrogenase (HSD3b) by immunofluorescence. Similar to the results of SF1 immunohistochemistry (Figure 1B), the numbers of steroidogenic cortical cells were decreased at $18.5 \mathrm{dpc}$ and these cells almost completely disappeared by P5 (Figure 1C). To investigate whether the loss of cortical cells resulted from increased cell death or reduced cell proliferation, we examined proliferation by staining for proliferation marker Ki67 and apoptosis by TUNEL assay. We found no apparent changes in the number of Ki67-positive cells in the KO cortex compared to the control (Figure $1 \mathrm{C}$ ). Using the TUNEL assay to evaluate apoptosis, we observed an increase of TUNEL- and steroidogenic enzyme 21-hydroxylase (CYP21)-double positive cells in the $\mathrm{KO}$ adrenal cortex starting at $14.5 \mathrm{dpc}$ (Figure 2). In the control adrenal, only few TUNEL-positive cells in the cortex were observed during development (0-2 cells per section). However in the KO cortex, significant increase in TUNEL-positive cells was observed at all time points (Figure 2, average of 25 cells per section). At P5, few apoptotic cells remained in the $\mathrm{KO}$ adrenal where almost all cortical cells were lost at this stage. As a result of loss of adrenal cortex, none of the Dicer1 KO animals survived beyond $\mathrm{P} 5$.

\section{Ablation of Dicer1 in the SF1-positive cells causes testis degeneration after birth}

Ablation of Dicer 1 mediated by Sf1/Cre inactivates Dicer 1 not only in the adrenal but also in the somatic cells of fetal testes and ovaries. Although $\mathrm{Sfl} / \mathrm{Cre}$ was activated in the adrenogonadal primordium, the $\mathrm{KO}$ testis did not show any abnormality during fetal life. Sertoli cell differentiation and testis cord formation in the fetal testes were comparable between control and $\mathrm{KO}$ as indicated by SOX9 staining (Figure 3). At the time of birth or P0, no morphological differences were found in the $\mathrm{KO}$ testis and epididymis (Figure 4A and 4B). At P2 and P5, the size of the $\mathrm{KO}$ testis remained similar to that at $\mathrm{PO}$ while the size of the control testis increased over time (Figure 4A). Testis cords, as outlined by staining for laminin, started to degenerate at $\mathrm{P} 2$ in the $\mathrm{KO}$ testis and by $\mathrm{P} 5$, only few testis cords were observed (Figure 4B and Additional File $1)$.

To investigate how loss of Dicer1 in the SF1-positive cells affects differentiation of somatic cells and germ cells in the testis, we examined markers specific for Sertoli cells (SOX9), germ cells (TRA98) [20], steroidogenic Leydig cells (HSD3b), and the proliferation marker Ki67 (Figure 5). No significant differences were observed in $\mathrm{KO}$ testis at P0 compared to the control. At P2, the number of testis cords in the KO testis was decreased (Figure 5A). We also observed a decrease in the number of proliferating Sertoli cells inside the testis cords (Figure 5B and Additional File 2). At P5, KO testes lost most of the testis cord structures and few cords were present. Dicer1 depletion affected not only testis cords but also Leydig cells in 


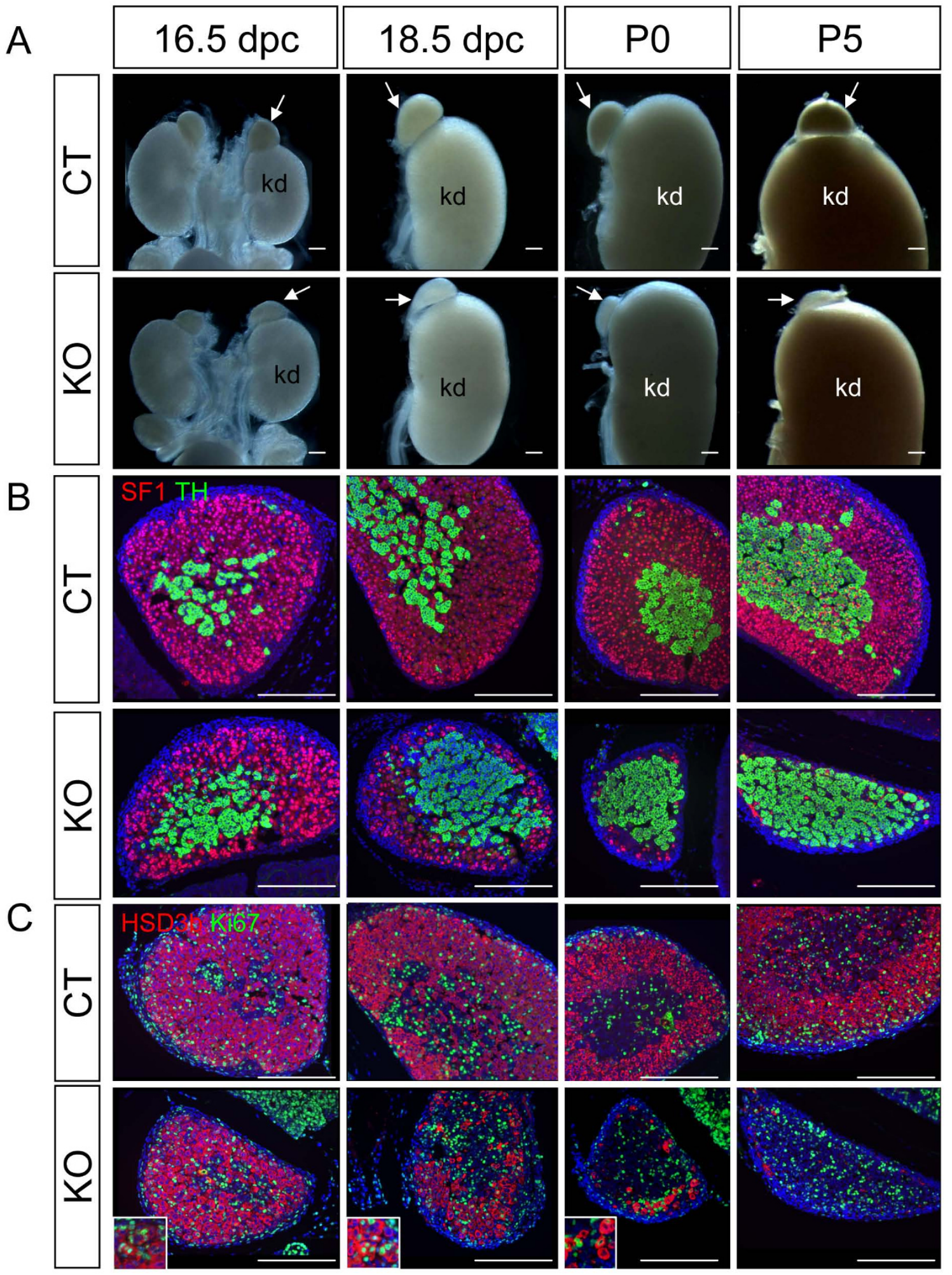

Figure 1 Effects of Dicer1 ablation on adrenal development. Adrenal glands from control (CT) or Sf1/Cre;Dicer1loxP/loxP (KO) embryos (16.5 and 18.5 $\mathrm{dpc}$ ), newborns (P0), and Day 5 neonates (P5) were collected for (A) gross morphological analysis, (B) immunofluorescence for SF1 (magenta), TH (green), and DAPI (blue), and (C) immunofluorescence for Ki-67 (green), HSD3b (magenta), and DAPI (blue). Higher magnification (2× of the original figure) of the proliferating cells is shown in the inlets. Arrow = adrenal; $k d=$ kidney. Scale bars represent $250 \mu \mathrm{m}$. 


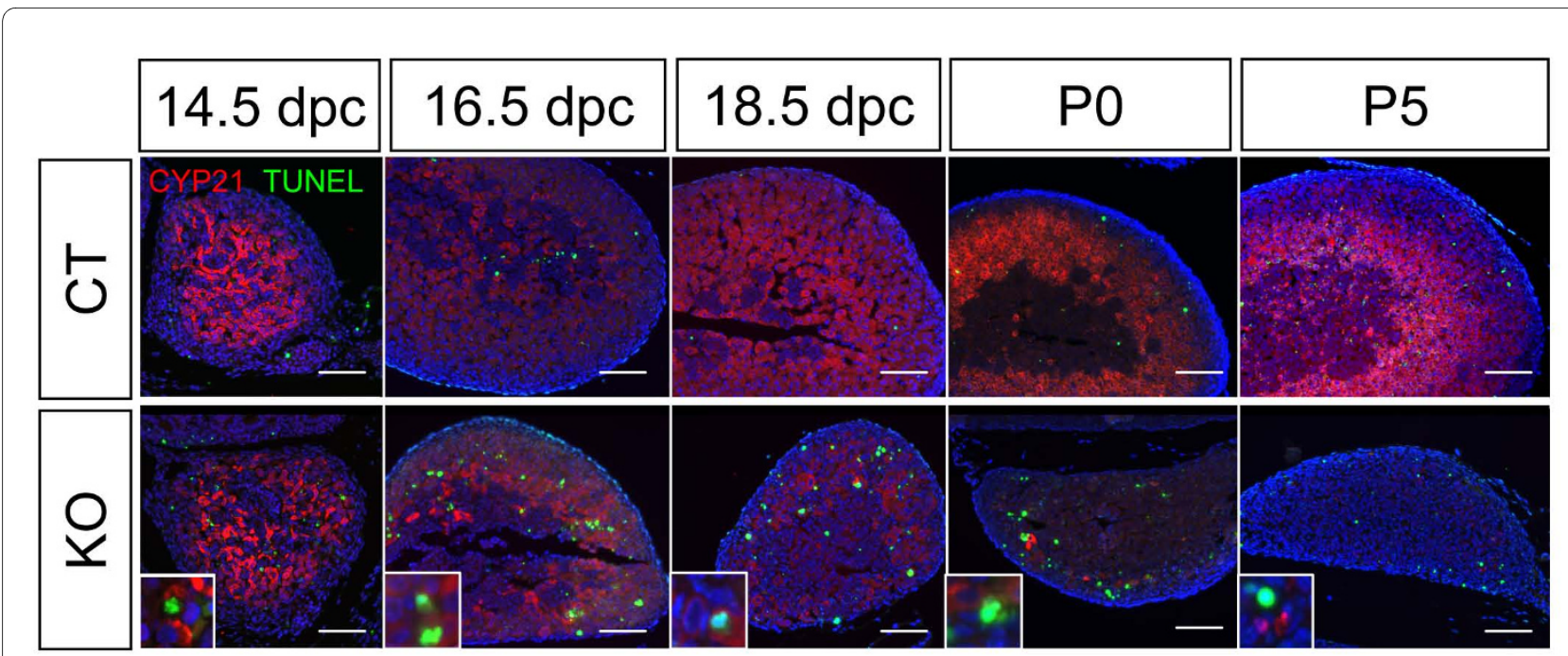

Figure 2 Effects of Dicer1 ablation on adrenal apoptosis. TUNEL assay was performed on sections of adrenals at $14.5 \mathrm{dpc}, 16.5 \mathrm{dpc}, 18.5 \mathrm{dpc}, \mathrm{PO}$, and P5. Green nuclear staining represents positive signals for fragmented DNA and blue staining was the DAPI nuclear counterstain. Immunofluorescence for CYP21 (magenta) was also performed on adrenal sections to label the adrenal cortex. Higher magnification ( $4 \times$ of the original figure) of the apoptotic cells is shown in the inlets. Scale bars represent $100 \mu \mathrm{m}$.

the interstitium. At P2, most of the HSD3b-positive Leydig cells disappeared and no Leydig cells were found at P5 (Figure 5B). It is known that Leydig cells at this stage are mitotically inactive $([21,22]$ and Figure $5 B)$; therefore, the decrease in Leydig cell number was probably not the result of proliferation problems.

To examine whether the degeneration of the $\mathrm{KO}$ testis results from increased cell death, we performed immunofluorescence for cleaved caspase-3 (CASP3), a marker for apoptosis. No CASP3-positive cells were found in the control testes during development (Figure 6A). In con-

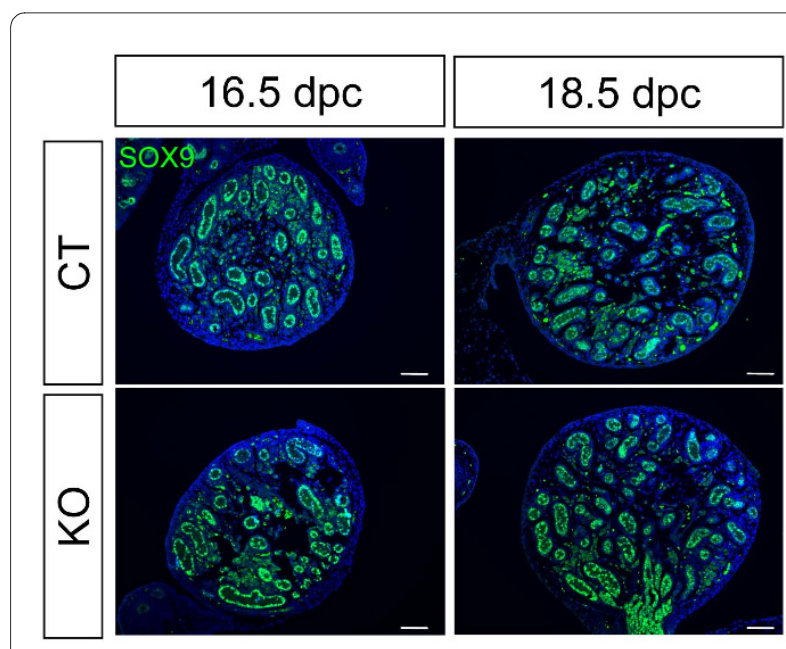

Figure 3 Effects of Dicer1 ablation on fetal testis development. Testes from control (CT) or Sf1/Cre;Dicer 1loxP/loxP (KO) embryos at 16.5 $\mathrm{dpc}$ and $18.5 \mathrm{dpc}$ were collected for immunofluorescence for SOX9 (green) and DAPI counterstain (blue). Scale bars represent $100 \mu \mathrm{m}$. trast, the $\mathrm{KO}$ testes had significant numbers of CASP3positive cells starting at $18.5 \mathrm{dpc}$ and becoming prominent at P0 and P2 (Figure 6A). By double staining with the germ cell marker TRA98 or the basement membrane marker laminin, we found that most of the CASP3-posi-

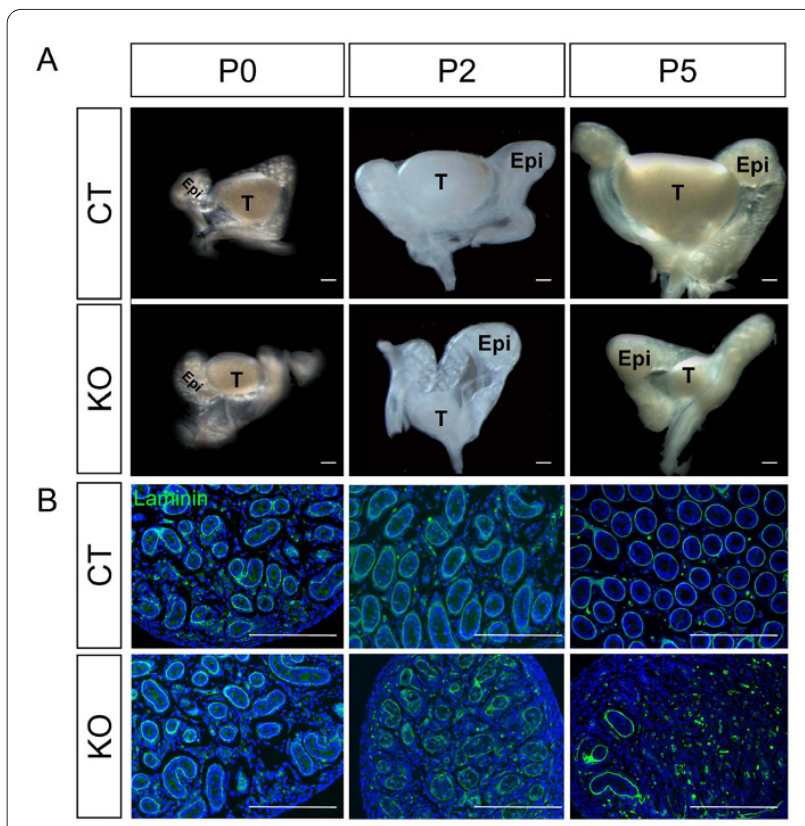

Figure 4 Effects of Dicer1 ablation on neonatal testis development. Testes from control (WT) or Sf1/Cre;Dicer1loxP/loxP (KO) newborns (P0), Day 2 (P2), and Day 5 (P5) neonates were collected for (A) Gross morphological analysis and (B) immunofluorescence for laminin (green) and DAPI counterstain (blue). Epi = epididymis; $\mathrm{T}=$ testis. Scale bars represent $250 \mu \mathrm{m}$ 


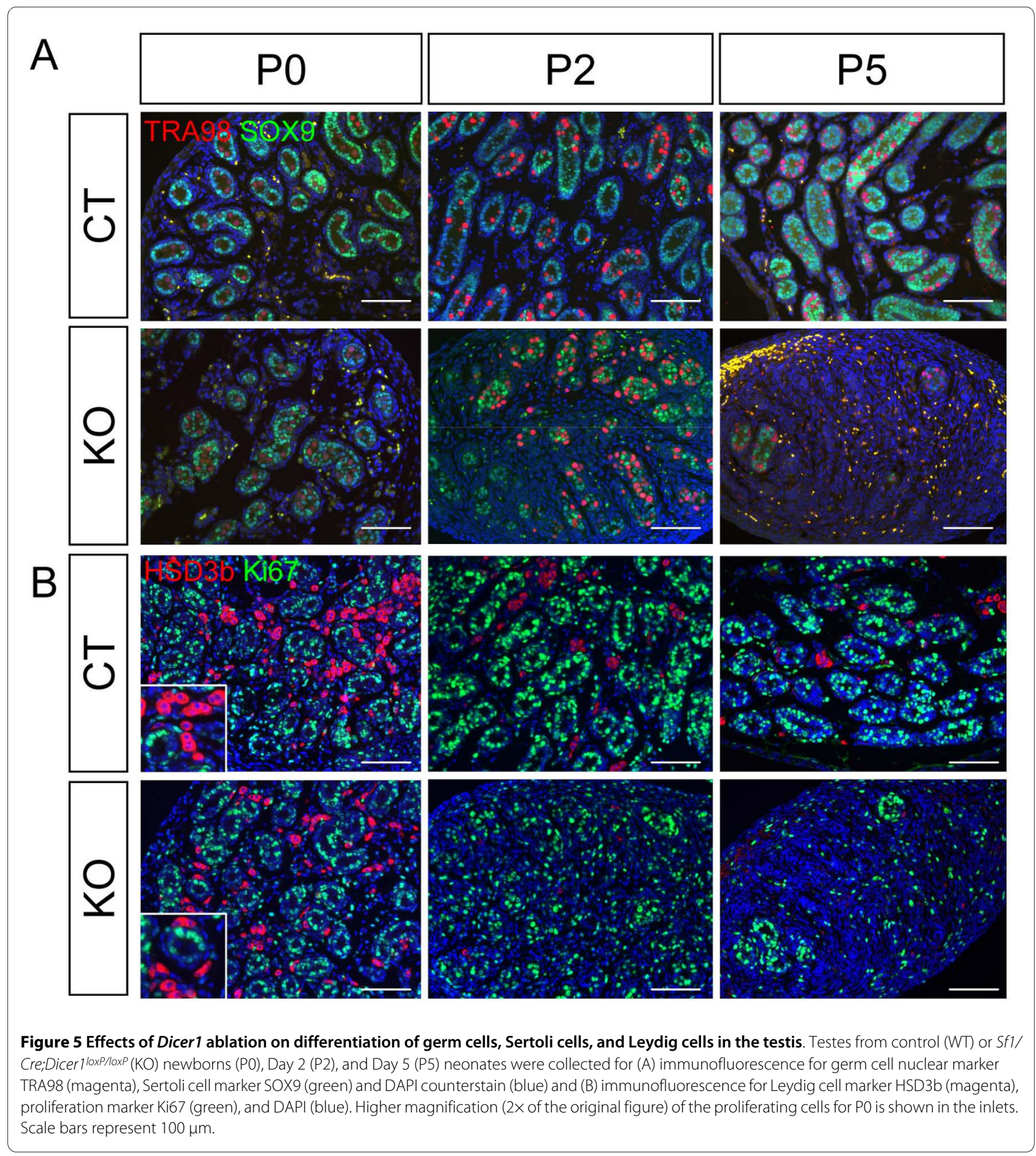

tive cells in P0 KO testes belonged to TRA98-negative Sertoli cells inside the testis cords and cells in the interstitium (Figure 6B and 6D). At P2, CASP3 staining was observed in both TRA98-positive germ cells and TRA98negative Sertoli cells inside the testis cords (Figure 6C) and only few CASP3-positive cells were found in the interstitium (Figure 6E).

\section{Ablation of Dicer 1 does not disturb fetal and neonatal} development of the ovary

Targeted gene deletion mediated by Sf1/Cre transgene occurs in all SF1-positive tissues, including the ovary [15]. In our lab, the aforementioned Sf1/Cre transgenic mouse line was used successfully to inactivate betacatenin in the fetal ovary [17]. We analyzed the Dicer1 

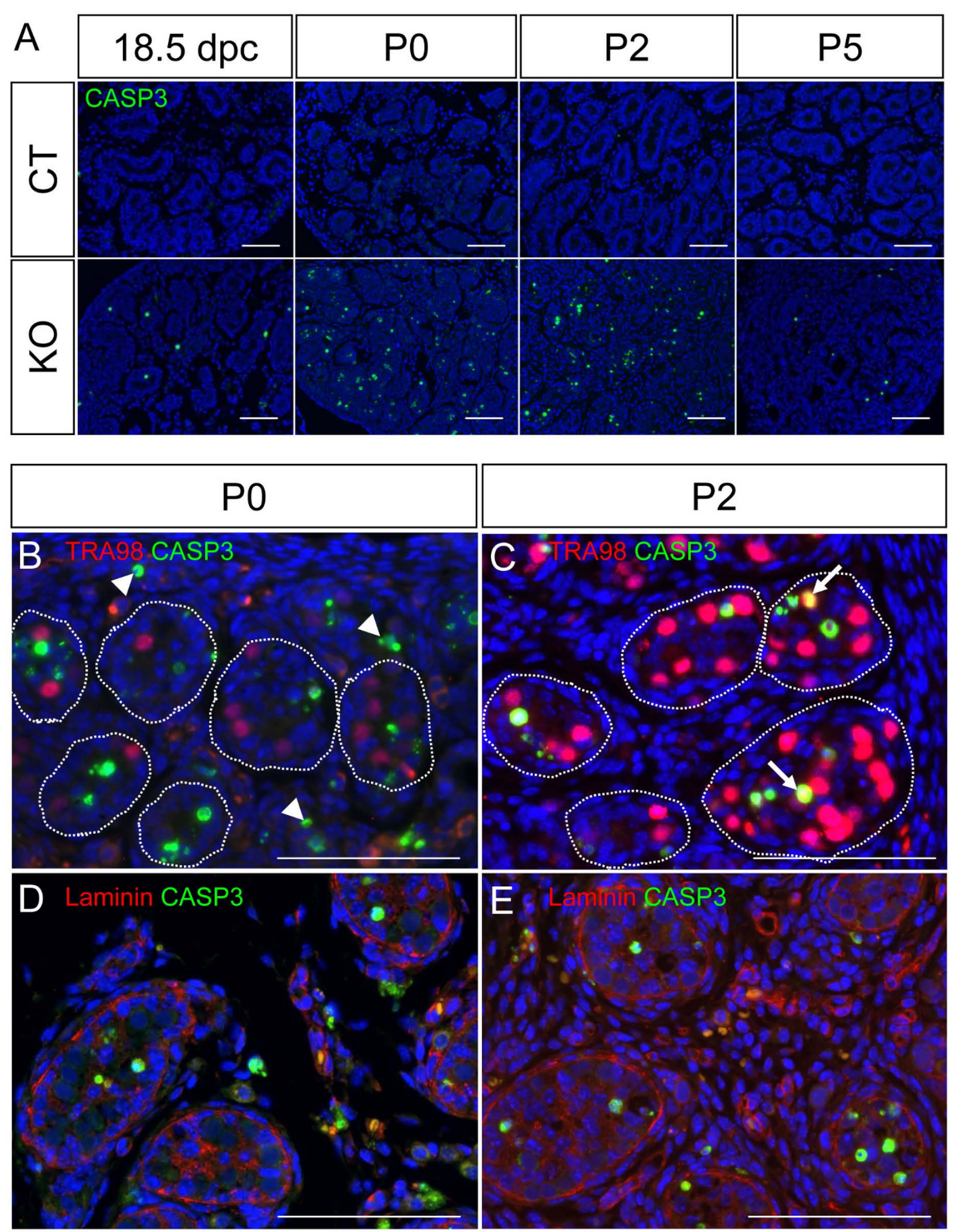

Figure 6 Effects of Dicer1 ablation on apoptosis in the testis. (A) Immunofluorescence for cleaved Caspase3 (CASP3) was performed on sections of testes at $18.5 \mathrm{dpc}, \mathrm{PO}, \mathrm{P} 2$, and P5. Green nuclear staining represented positive signals for apoptotic cells and blue staining was the DAPI nuclear counterstain. Double staining of CASP3 (green) and TRA98 or laminin (magenta) was performed on testes from P0 (B and D) and P2 (C and E) KO testes. Dotted lines mark the testis cords. Arrowhead = apoptotic cells outside the testis cord. Arrow = apoptotic germ cells. Scale bars represent $100 \mu \mathrm{m}$. 
KO ovary mediated by the same Sf1/Cre at fetal stages and up to P5 and found no differences in morphology and marker expression between control and $\mathrm{KO}$ ovaries (Figure 7 and Additional File 1, only P5 results are shown as representation). At $\mathrm{P} 5$, the size, staining patterns of cell specific markers (HSD3b and SF1 for somatic cells and TRA98 for germ cells), and markers for proliferation (Ki67) and apoptosis (CASP3) were indistinguishable between WT and KO ovaries (Figure 7).

\section{Discussion}

In the Sf1/Cre-mediated Dicer $1 \mathrm{KO}$ mice, adrenal cortical cells are the first SF1-positive population that undergoes apoptosis at fetal stages, followed by testicular Leydig cells and Sertoli cells, respectively. Adrenal degeneration in the Dicer 1 KO starts between 16.5-18.5 dpc and by the time of birth, adrenal cortical cells are almost completely abolished. In the testis, however, degeneration becomes apparent only after birth and progresses rapidly. Loss of somatic cells in the testes eventually leads to germ cells loss in the Dicer1 KO testis. By P5, almost all of the functional structures and cell types in the testis are no longer present. Intriguingly, ovaries, which derive from the same SF1-positive primordium as adrenal and testis, show no morphological and cellular changes from fetal stages to P5 in response to the loss of Dicer1. Increased apoptosis has been reported in tissues that lack Dicer1 [5-8]. Increased cell death in testes and adrenals in our study further suggests that Dicer1 and microRNAs processed by DICER play a universal role in maintaining cell survival.

In the adrenal, the cortical cells are derived from at least two sources: 1) the SF1-positive adrenal primordium, which forms the foundation of the organ and 2) SF1-negative capsular cells, which contribute to further growth of the adrenocortex [23-26]. It is known that loss of $S f 1$ leads to apoptosis of adrenal cortical cells and adrenal dysgenesis at birth $[14,27]$. Loss of Dicer 1 in the SF1positive cortical cells also leads to apoptosis of the cortex; however, the degeneration process occurs much later than that in the case of $S f 1$ KO. It is possible that DICERregulated miRNAs control genes that are critical for cortical cells survival, such as $S f 1$. However, in the Dicer $1 \mathrm{KO}$ adrenal, SF1 is still present in the remaining cortical cells. Depletion or mutation of Cited2, Wt1, and $P b x 1$ also resulted in prenatal adrenal dysgenesis in mouse embryos [28-30]. Involvement of Dicer and miRNAs in regulation of these genes in adrenal development remains to be determined.

Adrenocortical degeneration was also reported in $\beta$ catenin conditional $\mathrm{KO}$ mice [18]. $\beta$-catenin deficiency mediated by the same Sf1/Cre resulted in underdeveloped adrenal cortex; however, no apoptosis was found at fetal stages. These data suggest that regulation of adrenal development via $\beta$-catenin is probably independent from DICER-regulated miRNA machinery or vice versa.

Dicer and other components of the miRNA-mediated interference machinery are present in the testis, including

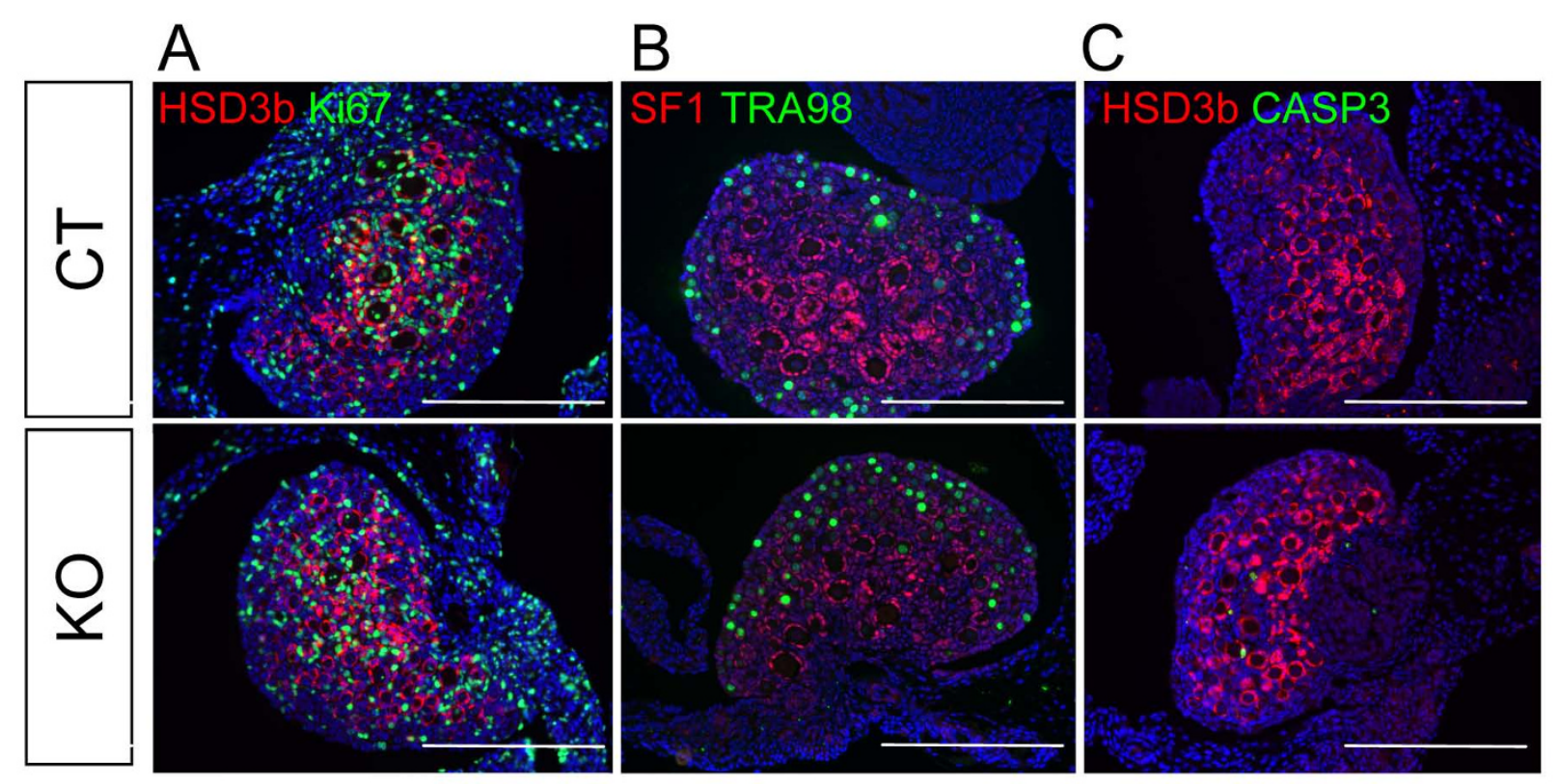

Figure 7 Effects of Dicer 1 ablation on ovary development. Ovaries from control (CT) or Sf1/Cre;Dicer 1loxp/loxP (KO) Day 5 neonate (P5) were collected for (A) immunofluorescence for Ki67 (green) and HSD3b (magenta), (B) immunofluorescence for TRA98 (green) and SF1 (magenta), (C) immunofluorescence for CASP3 (green) and HSD3b (magenta). All sections were counterstained with DAPI (blue). Scale bars represent $250 \mu \mathrm{m}$. 
germ cells and Sertoli cells [31-34]. Germ cell-specific Dicer1 KO mice were generated using the TNAP/Cre that is active in the primordial germ cells $[9,10]$. Loss of Dicer1 in germ cells led to defects in proliferation and differentiation of spermatogonia and abnormal morphology and motility of sperm $[9,10]$. Sertoli cell-specific Dicer1 KO mice was generated using the anti-Müllerian hormone Cre (Amh-cre) line that targets Sertoli cells starting at $\sim 15.5$ dpc [8]. Loss of Dicer1 in Sertoli cells resulted in impaired spermatogenic waves and complete absence of spermatozoa. In addition, increased Sertoli cell apoptosis was found at P5 and germ cells underwent apoptosis at P15, eventually leading to complete testis degeneration at P180. In our Sf1/Cre-mediated Dicer1 KO model, we targeted both Sertoli cells and Leydig cells at an earlier stage (10-11 dpc). We observed testicular degeneration at an earlier time point and in a more dramatic fashion than was reported in the Sertoli cell Dicer1 KO. In our model, almost all testicular structures and cell types were absent at P5. As expected, both Sertoli and Leydig cell populations underwent apoptosis albeit within different time frames (the number of Leydig cells decreases first, followed by Sertoli cells). Although male germ cells are negative for SF1, their survival was affected in the somatic cell-specific Dicer1 KO testis. This is expected as Sertoli cells are known to provide structural supports and differentiation cues to support spermatogenesis [35]. Although Leydig cells were also affected in our model, we do not believe that their demise is responsible for the germ cell loss phenotypes based on the fact that male germ cells are not known to respond to androgens, the major product of Leydig cells.

Dicer1 is also expressed in the female reproductive tract and the ovary, including oocytes, theca cells and granulosa cells [36-39]. Many miRNAs are synthesized in ovaries at different stages of folliculogenesis [40-42]. It has been reported that morphogenesis and function of the female reproductive tract were affected in the absence of Dicer1 [39]. To study the in vivo role of Dicer1 in the mouse ovary, granulosa cell specific Dicer 1 KO mice were generated by using Amhr2/Cre, which is expressed in granulosa cells of preantral and antral follicles [11,43-45]. Two different Dicer1-floxed strains were used and both showed that loss of Dicer1 in granulosa cells resulted in decreased ovulation rate, trapped oocytes in luteinized follicles and increased numbers of atretic follicles $[11,18,46]$. Fertilized oocytes collected from granulosa cell-specific Dicer1 KO females had decreased ability to progress to the two-cell stage [46]. We were not able to examine the consequence of loss of Dicer1 on folliculogenesis due to death of Dicer1 KO animals after P5 as a result of adrenal cortex degeneration. However at least at P5, Dicer1 KO ovaries show no signs of degeneration.

\section{Conclusions}

Based on findings from our lab and others, Sf1/Cre-medicated gene deletion occurs in adrenals and gonads at 1011 dpc. In the Sf1/Cre-mediated Dicer 1 KO embryos, defects in adrenals and testes did not become apparent until $18.5 \mathrm{dpc}$ and $\mathrm{P} 0$, respectively, and the ovaries were not affected. The extended delay between deletion of Dicer and the appearance of phenotypes suggests that Dicer and/or microRNAs have a substantial half-life [8]. It also raises the possibilities that (i) these organs have different turn-over rate of Dicer and/or Dicer-induced microRNAs, (ii) these three organs have different thresholds of tolerance toward the loss of Dicer1 and microRNAs, and/or (iii) Dicer and microRNAs play tissuespecific roles among these three organs. In the Sertoli cell-specific Dicer1 KO testis, the significant alternations in gene expression have already occurred at the time when structural changes are not yet detectable. We are currently testing these three possibilities by performing a time course analysis of changes in Dicer1 mRNA, Dicer protein and microRNAs in these three tissues after Dicer1 ablation.

\section{Methods}

\section{Generation of conditional Dicer 1 knockout mice}

Conditional Dicer 1 KO mice were generated by crossing Sf-1/Cre transgenic mice [15] with Dicer1f/f mice (Dicer $1^{\text {tmlBdh }}$, obtained from the Jackson Laboratory) $[5,6,9,16]$. The genetic background of these mice was mixed C57BL/6J and SV129. Female and male mice were paired together and checked for the presence of a vaginal plug the next morning. The day when the vaginal plug was detected was considered 0.5 day post coitum or dpc. Samples were collected at $14.5 \mathrm{dpc}, 16.5 \mathrm{dpc}, 18.5 \mathrm{dpc}$, birth (P0), postnatal day 2 and 5 (P2 and P5). The genotype was determined by polymerase chain reaction (PCR) of tail DNA [6,19]. All procedures described were reviewed and approved by the Institutional Animal Care and Use Committee at University of Illinois and were performed in accordance with the Guiding Principles for the Care and Use of Laboratory Animals. All experiments were performed on at least three animals for each genotype.

\section{Immunofluorescence}

The specimens were fixed in $4 \%$ paraformaldehyde/phosphate-buffered saline (PBS) at $4{ }^{\circ} \mathrm{C}$ overnight, and embedded in paraffin following standard procedures for sectioning. For immunofluorescence analysis, paraffin embedded sections were dewaxed and rehydrated in a series of alcohol/PBS gradient. The endogenous peroxidase activity was blocked by $3 \% \mathrm{H}_{2} \mathrm{O}_{2}$ in methanol for 8 minutes and rinsed with PBS 3 times for 5 minutes each. 
Slides were pretreated in $0.1 \mathrm{mM}$ citrate acid for $20 \mathrm{~min}$ utes in the microwave. After preincubating with $1.5 \%$ normal donkey serum in PBS for 30 minutes, sections were incubated with either anti-SF1, anti-CYP21 (1:1000, kindly provided by Dr. B-c Chung, Academia Sinica, Taiwan), anti-TH (1:1000, Millipore, Billerica, MA, USA), anti-3ßHSD, anti-SOX9 (1:1000, kindly provided by Dr. K. Morohashi, National Institutes of Natural Sciences, Japan.), anti-Laminin (1:500, Sigma-Aldrich, St. Louis, MO, USA), anti-TRA98 (1: 1000 kindly provided by Dr. H. Tanaka, Osaka University, Japan), anti-cleaved Caspase-3 (1:500, Cell Signaling, Danvers, MA, USA) or antiKi67 antibody (1:1000, BD Biosciences, San Jose, CA, USA) in PBST containing 1.5\% normal donkey serum at $4^{\circ} \mathrm{C}$ overnight. After rinsing with PBST, sections were incubated with secondary antibody for 30 minutes and processed for signal detection according to the manufacturer's protocol (TSA kit, PerkinElmer, Waltham, MA, USA). For double-fluorescent staining of anti-cleaved Caspase- 3 with other antibodies, staining of cleaved Caspase-3 were performed first as described above, samples then were double stained for the other antibodies using different fluorescent-label secondary antibodies. For other double-fluorescent staining, tissue sections were treated with two different primary antibodies generated from different species, followed by appropriate secondary antibodies. At least three animals were examined for each genotype.

\section{TUNEL assay}

TUNEL assay was performed on $5 \mu \mathrm{m}$ paraffin sections using Roche's TUNEL assay kit (Roche Co., Ltd., Indianapolis, IN, USA) according to the manufacturer's instructions.

\section{List of Abbreviations}

Amh: anti-Müllerian hormone; CT: control; CYP21: 21hydroxylase; HSD3b: $3 \beta$-hydroxysteroid dehydrogenase; KO: Knockout; PCR: polymerase chain reaction; PBS: phosphate-buffered saline; PBST: Phosphate Buffered Saline Tweeen-20; Sf1: Steroidogenic factor 1; TH: tyrosine hydroxylase; WT: wild type.

\section{Additional material}

Additional file $1 \mathrm{H} \& \mathrm{E}$ staining of adrenals, testes and ovaries of wild type and knockout mice. Adrenals, testes and ovaries from control (CT) or Sf1/Cre;Dicer 1 loxP/10xP (KO) postnatal day 5 (P5) neonates were processed for H\&E staining. Images in the inlets were higher magnification. Scale bars represent $100 \mu \mathrm{m}$.

Additional file 2 Proliferating cells in the testis cords of wild type and knockout mice. Testes from P2 and P5 control (CT) or Sf1/Cre;Dicer 1loxP/loxP (KO) neonates were examined by immunofluorescence for Ki67 (green) and SOX9 (magenta). Scale bars represent $100 \mu \mathrm{m}$.

\section{Authors' contributions}

$\mathrm{CJH}$ carried out all experimental works. $\mathrm{CJH}$ and HHY designed the experiments. CJH drafted the manuscript, which was edited by HHY. All authors have read and approved the final manuscript.

\section{Acknowledgements}

We would like to thank the following collaborators for providing the antibodies: Dr. Bon-chu Chung (SF1 and CYP21 antibodies), Dr. Ken Morohashi (SOX9 antibody), and Drs. Hiromitsu Tanaka and Yoshitake Nishimune (TRA98 antibody). We also appreciate all of the Yao lab members for their assistance and support. This study was funded by National Institute of Health (HD046861 and HD059961 to H.H.Y) and the Billie Field Memorial Fellowship to C.J.H. We would like to dedicate this study to our collaborator and friend Dr. Keith Parker, who passed away on December 13, 2008.

\section{Author Details}

Department of Veterinary Biosciences, University of Illinois, Urbana, IL, USA

Received: 20 November 2009 Accepted: 11 June 2010

Published: 11 June 2010

\section{References}

1. Bartel DP: MicroRNAs: genomics, biogenesis, mechanism, and function. Cell 2004, 116:281-297.

2. Lim LP, Lau NC, Garrett-Engele P, Grimson A, Schelter JM, Castle J, Bartel DP, Linsley PS, Johnson JM: Microarray analysis shows that some microRNAs downregulate large numbers of target mRNAs. Nature 2005, 433:769-773.

3. Filipowicz W, Bhattacharyya SN, Sonenberg N: Mechanisms of posttranscriptional regulation by microRNAs: are the answers in sight? Nat Rev Genet 2008, 9:102-114.

4. Bernstein E, Kim SY, Carmell MA, Murchison EP, Alcorn H, Li MZ, Mills AA, Elledge SJ, Anderson KV, Hannon GJ: Dicer is essential for mouse development. Nat Genet 2003, 35:215-217.

5. Harris KS, Zhang Z, McManus MT, Harfe BD, Sun X: Dicer function is essential for lung epithelium morphogenesis. Proc Natl Acad Sci USA 2006, 103:2208-2213.

6. Harfe BD, McManus MT, Mansfield JH, Hornstein E, Tabin CJ: The RNasell enzyme Dicer is required for morphogenesis but not patterning of the vertebrate limb. Proc Natl Acad Sci USA 2005, 102:10898-10903.

7. Chen JF, Murchison EP, Tang R, Callis TE, Tatsuguchi M, Deng Z, Rojas M, Hammond SM, Schneider MD, Selzman CH, et al:: Targeted deletion of Dicer in the heart leads to dilated cardiomyopathy and heart failure. Proc Natl Acad Sci USA 2008, 105:2111-2116.

8. Papaioannou MD, Pitetti JL, Ro S, Park C, Aubry F, Schaad O, Vejnar CE, Kuhne F, Descombes P, Zdobnov EM, et al:: Sertoli cell Dicer is essential for spermatogenesis in mice. Dev Biol 2009, 326:250-259.

9. Maatouk DM, Loveland KL, McManus MT, Moore K, Harfe BD: Dicer1 is required for differentiation of the mouse male germline. Biol Reprod 2008, 79:696-703.

10. Hayashi K, Chuva de Sousa Lopes SM, Kaneda M, Tang F, Hajkova P, Lao K, O'Carroll D, Das PP, Tarakhovsky A, Miska EA, Surani MA: MicroRNA biogenesis is required for mouse primordial germ cell development and spermatogenesis. PLoS One 2008, 3:e1738.

11. Lei L, Jin S, Gonzalez G, Behringer RR, Woodruff TK: The regulatory role of Dicer in folliculogenesis in mice. Mol Cell Endocrinol 2010, 315:63-73.

12. Ikeda Y, Shen WH, Ingraham HA, Parker KL: Developmental expression of mouse steroidogenic factor-1, an essential regulator of the steroid hydroxylases. Mol Endocrinol 1994, 8:654-662.

13. Keegan CE, Hammer GD: Recent insights into organogenesis of the adrenal cortex. Trends Endocrinol Metab 2002, 13:200-208.

14. Luo $X$, Ikeda $Y$, Parker KL: A cell-specific nuclear receptor is essential for adrenal and gonadal development and sexual differentiation. Cell 1994, 77:481-490

15. Bingham NC, Verma-Kurvari S, Parada LF, Parker KL: Development of a steroidogenic factor $1 /$ Cre transgenic mouse line. Genesis 2006 , 44:419-424

16. Soukup GA, Fritzsch B, Pierce ML, Weston MD, Jahan I, McManus MT, Harfe BD: Residual microRNA expression dictates the extent of inner ear development in conditional Dicer knockout mice. Dev Biol 2009, 328:328-341. 
17. Liu CF, Bingham N, Parker K, Yao HH: Sex-specific roles of beta-catenin in mouse gonadal development. Hum Mol Genet 2009, 18:405-417.

18. Kim AC, Reuter AL, Zubair M, Else T, Serecky K, Bingham NC, Lavery GG, Parker KL, Hammer GD: Targeted disruption of beta-catenin in Sf1expressing cells impairs development and maintenance of the adrenal cortex. Development 2008, 135:2593-2602.

19. Barsoum IB, Bingham NC, Parker KL, Jorgensen JS, Yao HH: Activation of the Hedgehog pathway in the mouse fetal ovary leads to ectopic appearance of fetal Leydig cells and female pseudohermaphroditism. Dev Biol 2009, 329:96-103.

20. Tanaka H, Pereira LA, Nozaki M, Tsuchida J, Sawada K, Mori H, Nishimune Y: A germ cell-specific nuclear antigen recognized by a monoclonal antibody raised against mouse testicular germ cells. Int J Androl 1997 20:361-366

21. Habert $R$, Lejeune $H$, Saez JM: Origin, differentiation and regulation of fetal and adult Leydig cells. Mol Cell Endocrinol 2001, 179:47-74.

22. Orth JM: Proliferation of Sertoli cells in fetal and postnatal rats: a quantitative autoradiographic study. Anat Rec 1982, 203:485-492.

23. Huang CC, Miyagawa S, Matsumaru D, Parker KL, Yao HH: Progenitor cell expansion and organ size of mouse adrenal is regulated by sonic hedgehog. Endocrinology 151:1119-1128.

24. King P, Paul A, Laufer E: Shh signaling regulates adrenocortical development and identifies progenitors of steroidogenic lineages. Proc Natl Acad Sci USA 2009, 106:21185-21190.

25. Zubair M, Parker KL, Morohashi K: Developmental links between the fetal and adult zones of the adrenal cortex revealed by lineage tracing. $\mathrm{Mol}$ Cell Biol 2008, 28:7030-7040

26. Ching S, Vilain E: Targeted disruption of Sonic Hedgehog in the mouse adrenal leads to adrenocortical hypoplasia. Genesis 2009, 47:628-637.

27. Gut P, Huber K, Lohr J, Bruhl B, Oberle S, Treier M, Ernsberger U, Kalcheim C, Unsicker K: Lack of an adrenal cortex in Sf1 mutant mice is compatible with the generation and differentiation of chromaffin cells. Development 2005, 132:4611-4619

28. Else T, Hammer GD: Genetic analysis of adrenal absence: agenesis and aplasia. Trends Endocrinol Metab 2005, 16:458-468.

29. Schnabel CA, Selleri L, Cleary ML: Pbx1 is essential for adrenal development and urogenital differentiation. Genesis 2003, 37:123-130

30. Val P, Martinez-Barbera JP, Swain A: Adrenal development is initiated by Cited 2 and $\mathrm{Wt} 1$ through modulation of Sf-1 dosage. Development 2007, 134:2349-2358.

31. Ro S, Park C, Sanders KM, McCarrey JR, Yan W: Cloning and expression profiling of testis-expressed microRNAs. Dev Bio/ 2007, 311:592-602.

32. Gonzalez-Gonzalez E, Lopez-Casas PP, del Mazo J: The expression patterns of genes involved in the RNAi pathways are tissue-dependent and differ in the germ and somatic cells of mouse testis. Biochim Biophys Acta 2008, 1779:306-311.

33. Yan N, Lu Y, Sun H, Tao D, Zhang S, Liu W, Ma Y: A microarray for microRNA profiling in mouse testis tissues. Reproduction 2007, 134:73-79.

34. Kotaja N, Bhattacharyya SN, Jaskiewicz L, Kimmins S, Parvinen M, Filipowicz W, Sassone-Corsi P: The chromatoid body of male germ cells: similarity with processing bodies and presence of Dicer and microRNA pathway components. Proc Natl Acad Sci USA 2006, 103:2647-2652

35. Jegou B: The Sertoli cell. Baillieres Clin Endocrinol Metab 1992, 6:273-311.

36. Nicholson RH, Nicholson AW: Molecular characterization of a mouse cDNA encoding Dicer, a ribonuclease III ortholog involved in RNA interference. Mamm Genome 2002, 13:67-73.

37. Murchison EP, Stein P, Xuan Z, Pan H, Zhang MQ, Schultz RM, Hannon GJ: Critical roles for Dicer in the female germline. Genes Dev 2007 21:682-693.

38. Fiedler SD, Carletti MZ, Hong X, Christenson LK: Hormonal regulation of MicroRNA expression in periovulatory mouse mural granulosa cells. Biol Reprod 2008, 79:1030-1037.

39. Pastorelli LM, Wells S, Fray M, Smith A, Hough T, Harfe BD, McManus MT, Smith L, Woolf AS, Cheeseman M, Greenfield A: Genetic analyses reveal a requirement for Dicer1 in the mouse urogenital tract. Mamm Genome 2009, 20:140-151

40. Mishima T, Takizawa T, Luo SS, Ishibashi O, Kawahigashi Y, Mizuguchi Y, Ishikawa T, Mori M, Kanda T, Goto T: MicroRNA (miRNA) cloning analysis reveals sex differences in miRNA expression profiles between adult mouse testis and ovary. Reproduction 2008, 136:811-822.
41. Ro S, Song R, Park C, Zheng H, Sanders KM, Yan W: Cloning and expression profiling of small RNAs expressed in the mouse ovary. RNA 2007, 13:2366-2380

42. Yao N, Lu CL, Zhao JJ, Xia HF, Sun DG, Shi XQ, Wang C, Li D, Cui Y, Ma X: A network of miRNAs expressed in the ovary are regulated by FSH. Front Biosci 2009, 14:3239-3245.

43. Jamin SP, Arango NA, Mishina Y, Hanks MC, Behringer RR: Requirement of Bmpr1a for Mullerian duct regression during male sexual development. Nat Genet 2002, 32:408-410

44. Jorgez CJ, Klysik M, Jamin SP, Behringer RR, Matzuk MM: Granulosa cellspecific inactivation of follistatin causes female fertility defects. Mol Endocrinol 2004, 18:953-967.

45. Gonzalez G, Behringer RR: Dicer is required for female reproductive tract development and fertility in the mouse. Mol Reprod Dev 2009, 76:678-688

46. Nagaraja AK, Andreu-Vieyra C, Franco HL, Ma L, Chen R, Han DY, Zhu H, Agno JE, Gunaratne PH, DeMayo FJ, Matzuk MM: Deletion of Dicer in somatic cells of the female reproductive tract causes sterility. $\mathrm{Mol}$ Endocrinol 2008, 22:2336-2352.

doi: 10.1186/1471-213X-10-66

Cite this article as: Huang and Yao, Inactivation of Dicer1 in Steroidogenic factor 1-positive cells reveals tissue-specific requirement for Dicer1 in adrenal, testis, and ovary BMC Developmental Biology 2010, 10:66

\section{Submit your next manuscript to BioMed Central and take full advantage of:}

- Convenient online submission

- Thorough peer review

- No space constraints or color figure charges

- Immediate publication on acceptance

- Inclusion in PubMed, CAS, Scopus and Google Scholar

- Research which is freely available for redistribution 